Afruz M. Gurbanova', Bahar I. Ismayilova ${ }^{2}$

DOI: 10.25045/jpis.v09.i1.08

${ }^{1,2}$ Institute of Information Technology of ANAS, Baku, Azerbaijan

1afruz1961@gmail.com, ${ }^{2}$ bahar_ismayilova@yahoo.com

\title{
SOLUTION TO PROBLEMS IN TEACHING INFORMATICS THROUGH APPLICATION OF EDUCATIONAL GAMES AND INTELLECTUAL TESTS
}

The article explores the problems faced during the teaching of Informatics. It highlights the importance of educational games, intellectual tests and crossword puzzles for increasing the activity of students, the quality of instruction, and the acquisition and evaluation of knowledge. Moreover, the article substantiates the necessity for the development of various electronic terminology tests, crossword puzzles and computer games as the evaluation mechanisms of the intellectual level of individuals in certain knowledge fields. In this regard, non-standard methods used in the education system of foreign countries are analyzed, and some solutions are proposed.

Keywords: education quality, knowledge evaluation, motivation, educational games, computer games, terminology tests, crossword puzzles.

\section{Introduction}

One of the factors influencing the quality of teaching students is their motivation. Motivation refers to the processes that determine the targeted activity and to the factors that affect the active and passive behavior. For this reason, it is important to find out the answers to following questions in order to understand how to raise motivation of students for learning: how is the persistence in achieving the goal determined when performing any action? what does determine and shape the internal motivation of trainees? What external factors are driving the motivation of individuals to reach the target? According to scholars, the higher the level of motivation for pupils to study any subject, the higher the quality of their knowledge acquisition is [1].

The fact that most pupils and young people use information technology and the Internet particularly for fun and entertainment is one of the actual problems of modern times. In Informatics classes, pupils are more motivated by computer games. This, in turn, motivates the satisfactory percentage of knowledge acquisition, the ability to understand theoretical materials and terms, and the activity in the learning process. Pedagogical experience shows that the motivation of students for studying Informatics is gradually decreasing. For this reason, the motivation of the students may be increased with the use of computer games as a source of information and as a mechanism for knowledge control when learning a topic in informatics classes. As a result, the quality of teaching will increase [2]. The methods and tools used in the classes and the correct selection of working forms is of great importance for the solution of this problem. The use of interactive tests, crossword puzzles and educational games in both the learning and evaluation processes (diagnostic, formative, summative) in each subject is one of the key tools for comprehensive development of education.

An important part of studying any subject is the perception of its conceptual apparatus. Terminological tests on any subject help using the concepts correctly and in place and independently. In these tests, the definition of the concept is used as a question and one of the options is correct. When it comes to questionable options, the relevant thematic section of the subject, vocabulary and surveys should be referred [3]. Problems occur when students cannot remember the specific terms, i.e., the presence of a large number of terms to remember, complicated descriptions of the teaching material, and sometimes lack of desire to work with terms complicates the situation.

Studies show that intellectual tests, crossword puzzles, and curriculum-based computer games increase creativity, perception and decision-making skills, and improve body and eye-handling in the learning process. The top players are able to manage on the tasks four times faster than others [4]. 
The Terminology Testing Tutorial created in PowerPoint, uses triggers and hyper-references [5]. This kind of test-tutorials offers a few questions, each of which comprises the interpretation and meaning of the term. Students revise and strengthen the learned material by choosing one correct answer out of three options.

On the other hand, this approach increases the ability of players to perform multiple tasks at the same time. For example, a person can normally pay attention to no more than four things at a time. Unlikely, an experienced player can work with more than six things at the same time without mixing them. Research shows that $42 \%$ of computer and video players, who are female, can handle 3D objects more skillfully than men [6].

Electronic games have also negative effects. Brain scanning of players shows that video games propagating violence and cruelty can change the functions of brain of a healthy young people. Thus, after playing game for a week, several irregularities may occur in the activity of certain parts of brain responsible for emotional control. Other studies confirm that excess weight, depression, and self-esteem in some games are interrelated [7].

Most games promoting violence and cruelty have been confirmed to have a strong effect on the brain. This causes parents' anxiety. Researchers believe that educational games that have strong effects are more important to be developed. It has been proven repeatedly that educational computing games are a highly effective tool for learning in classes and in extracurricular activities. Those who play games often have critical attitudes to the problems they encounter and find different solutions. The player will further benefit from the skills gained through the games, and will play more successfully. Thus, these skills are constantly improving in the course of game. Unlike the learning process in the classroom, the player receives immediate information about his/her success or failure, and can correct his/her mistakes. This also helps the player to develop skills in a certain trend throughout the process. Therefore, the exploration of educational games, their classification for separate criteria and their use in classes and extracurricular activities, methodological, psychological and technical training of teachers for successful performance of curriculum increase the quality of training and intellectual level of trainees. All above may also solve some problems occurring in the assessment of students.

The results of the special federal tests measuring the intellectual abilities of American schoolchildren in admission to high schools are of great importance. These tests measure the knowledge and skills of students, their intellectual abilities in specific subjects, their logic and mathematical thinking, vocabulary and its usage skills [8]. The use of interactive tests containing gaming elements in the study of disciplines at elementary and secondary schools makes the learning process more interesting and helps students to shape and develop knowledge, skills and values in different areas and use them for teaching purposes.

\section{History of educational games}

Playing a game is one of the aspects of the natural and universal human activity. Throughout the decades, as a source of inspiration, games have motivated people to study actively and vigorously. Games began to be used in education in the 1900s. The use of paper-based teaching games was popular in the 1960-1970s. However, in the 1970s, this popularity decreased under the influence of the movement "Back to basics". The surveys revealed that the trainees during those years performed poorer results, and therefore, deepened curriculums started to be used to implement reforms and focus on reading, writing and improving mathematical skills.

With the widespread expansion of individual computers in the 1980s, the use of teaching games such as Oregon Trail, Math Blaster and Number Munchers was vast. The Oregon Trail is the first educational computer game widely used in North American schools [9].

Although these games were popular among both teachers and learners, they were also critical of their use in teaching. According to critics, these games did not fully provide the player with new types of learning tools and deprived them of experience and active learning. 
In the 1990s, new and advanced games, such as "The Incredible Time Machine" and "Dr. Brain", were developed to assist children apply and analyze different and innovative thinking, knowledge and skills. However, these games were not popular among teachers. Because, it was very difficult to use new games in teaching process and curriculum (especially, in higher classes), and there was a time-related problem.

In the early 2000s, various types of educational games, especially for younger students, were designed. Most of these games were not computer games, but were used for other types of traditional game systems such as console (control panel). In 1999, LeapFrog Enterprises presented the game LeapPad, which was used with a cartridge interactive book. Based on the popularity of the traditional handheld system such as Nintendo's "Game Boy", the game system called "Leapster" was designed in 2003. This system was based on arcade (action) games integrated with curriculum content [10].

\section{"Serious games"}

In 2002, an initiative called "Serious Game Movement" was launched by Woodrow Wilson International Center for Scholars with David Rejecsk and Ben Sawyer's initiative, outside the formal education sector. "Serious Game" are the developing computer games that are of intellectual and training nature, specifically in the government or corporate training, education, health, politics and social spheres for strategic and competition purposes [11].

The US military servants were the main consumers and manufacturers of the "serious games". The aim of the military servants was to train different skills for their employees: to comprehend any situation, cognize the environment, make right decisions, communicate, and use new technologies. The first "serious game" was the 1980's Atari project - Army Battlezone intended for military exercises and training, however did not meet expectations. Later, the other two "serious games" - "American Army" (2002) and "Full Spectrum Warrior" (2004) were developed and handed over to the military.

"Serious games" are the educational games designed for use in teaching. They have a clear structure, purpose, results and practical application. These features distinguish "serious games" from entertaining games. "Serious games" can apply the player's experience in challenging situations using new modeling and visualization technologies [12].

It should be noted that "serious games" are mostly used in extracurricular activities (including adult learning) and not very popular in formal education due to the following reasons: the games may not meet the goals of formal education; their application may not be in accordance with the schedule; teachers cannot successfully use "serious games" in teaching and so on. To make the situation clearer, it is crucial to analyze the purpose, meaning and significance of serious games.

Serious games have always been more popular in formal education, professional training, health, advertising, politics and social spheres. Various educational games with different features and purposes are created [13].

\section{Characteristics of educational games}

Digital games are characterized by the following four signs:

- purpose;

- rules system;

- feedback system;

- voluntary participation.

Educational games are based on voluntary activity and assist players to compare and analyze their performance by evaluating certain results (winning, losing) and feedback through scoring. Educational games are often very useful and differ from other games as they are useful in terms of 
gaining knowledge and intellectual skills and values in certain academic content. Different types and functions of these games serve to assimilate and evaluate teaching materials (Figure 1).

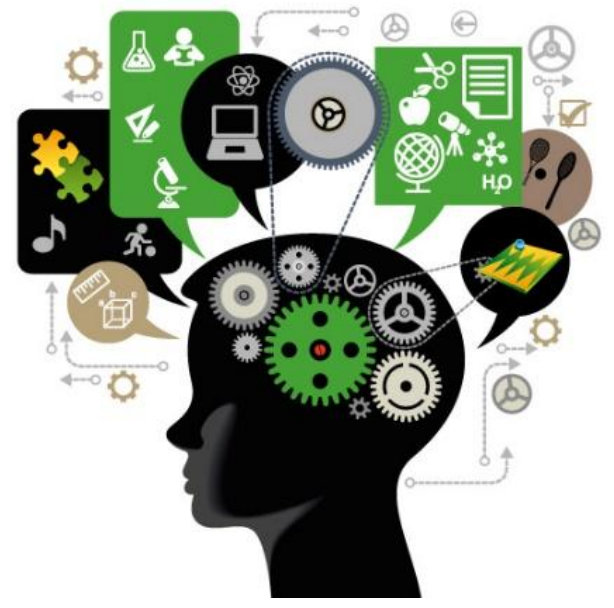

Figure 1. Mechanisms for mastering educational games

Short-term games offer tools for practical and purposeful concepts. They are individual games that are especially attractive to schoolchildren and can be easily selected. During short-term games offer training, practice, simple modeling, visualization, and other interactive activities. Such games are popular in schools. This type of gaming products is widely used in teaching, covering many areas and enabling to shape and improve many skills in a short time. They are also accessible and understandable to teachers.

Unlike short-term games, long-term games have a strong scientific-research base and are aimed at forming a higher level of academic thinking skills, which is the requirement of the $21 \mathrm{st}$ century. These games are not so suitable for use in school time, but are very useful in extracurricular activities, projects and research associations as experimental sources. Long-term games cannot be used at one lesson. Thus the end of the game usually takes several sessions, sometimes a few weeks. Long-term games provide the development of skills and habits, such as critical and logical thinking, problem solving, creativity, collaboration, creativity and communication.

Surveys show that it is more effective to use specific long-term games compared to some typical lectures. For example, it was revealed that the comprehension with Supercharged was accounted for 28\%, with Geography Explorer - 15-40\%, and with Virtual Cell mobile biology game - 30-63\%. The quality of studies with the game River City was increased by $14 \%$ for the Blevel students and by $37 \%$ for D-level students [6].

Recent studies also confirm that the number of players of long-term educational games has increased dramatically. These games motivate students to study and engage actively with virtual practice. Unlike many training-related products, long-term games, where learning and learning are integrated, are proven to be more exciting and attractive.

The authors of the report by the United States Committee on Science Learning at the National Research Council have concluded that simulation, modeling and games have a great potential to increase the rate of comprehension in the classes. Because, they can individualize the learning process in accordance with the pace, curiosity and capabilities of students. They provide the comprehension of learning content ensuring experiments and eliminating constraints in virtual environments, laboratories and experiments [14].

Since the time required for long-term games is a significant obstacle to their widespread use, these games can easily be used as an element of homework. However, the results, strategies and homework can be discussed during the lesson. 
Research and development of educational games have always been a long-lasting process. Special concern is the result of research on the effectiveness of such games. Thus, one should be careful when choosing the game taking into account the age, interest and potential of players. Most studies conducted in foreign universities recommend involving students in educational games in academic studies for a few weeks assessing the environment.

Hence, educational games have a great impact on the development of critical thinking and skills required in the 21 st century.

\section{Interactive training tools}

Interactive training tools or small teaching aids or online tutorials can easily be integrated into a larger curriculum. For example, BrainPOP contains over 1000 animated lessons where interactive elements are added as quizzes (Figure 2). These short lessons cover the areas such as social sciences, mathematics, English, technology, music, art, science and health and are designed in accordance with state educational standards [15].

This site was very popular in the consumer market being gradually used at schools. With the use of these games, a teacher is able to easily plan in what part and for what the game will be used for example for memorizing mathematical concepts and rules, getting information about any historical event. A new product of BrainPOP namely BrainPOPJr is also available for younger children [16]. The web site now links them with various free educational games through the GameUp portal.

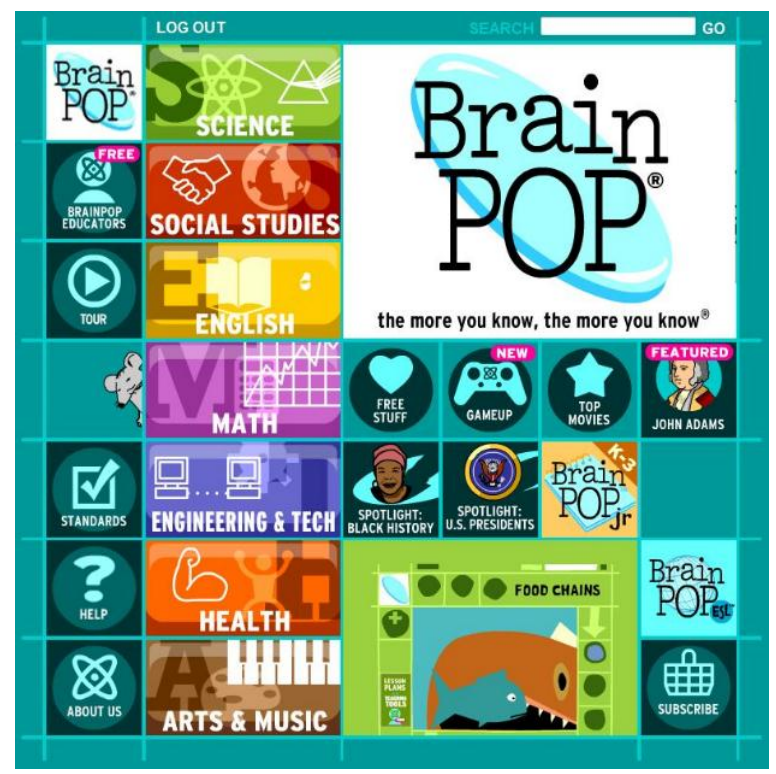

Figure 2. BrainPop K-12 - Educational Sites Group [15]

\section{Role-playing games}

In role-playing games, players act through their personalities, go through different paths, and return to their previous research places. Such games are particularly useful in social spheres. For example, when pupils are engaged in history, they face some problems with understanding the concept of slavery or citizenship. In this case, role-playing games have a significant impact on the perception of the material. The first role-playing games as Oregon Trail have been very successful in schools.

iCivics is a training game founded by a former US Supreme Court judge, S.D. O'Connor [17]. The game is designed to encourage young people to be active citizens and participants of the US democracy. The games modelling the situations such as "One Day President" or "Dispute at 
the Supreme Court" meet state standards for education and include teacher training materials, lesson plans and presentations in PowerPoint.

River City, the US National Science Foundation funded research project, provides interactive computer simulators for secondary school students, which include appropriate teaching content in accordance with the US National Science Education Standards and the National Educational Technology Standards [18]. The developers of River City were well aware of the challenges associated with the integration of games into the formal education environment, the problems typical for secondary school students, joint activities, evaluation, and teachers' unwillingness on learning new technologies. They tried to solve problems, as far as possible, through developing and upgrading the product and expanding the application. Finally, after several years of successful research and development, River City was ready to introduce it to the sales market.

In order to use intellectual computer games in the school education system, a teacher had to determine the place and role in the learning process, and use the game and learning elements together. Different tasks are given during the game: model, drawing, writing or verbal guides.

Thus, students get acquainted with different types of information, transmission methods and presentation forms. Students are easily involved in gaming activities. The effectiveness of the game depends primarily on the systematic use of didactic exercises and the program of the game.

\section{Crosswords}

One of the key issues in the preparation of crosswords, which is a kind of intellectual game, is to formulate and use various questions. The use of crossword puzzles is more effective and convenient for providing terminological literacy of students. Crossword is a gaming technique where the word is found according to its definition.

Each teaching topic proposes its crossword classification, which is derived from the specificity of the given subject matter. Therefore, taking the purpose of the lesson eases the matter [19].

Crossword helps to:

- to organize the free work;

- $\quad$ to rise an interest in the subject;

- to shape terminological literacy, in other words, to adopt the terminology apparatus of the subject more easily.

Advantages of crossword as a teaching method are as follows:

- provides details of certain sections and difficult subjects of curriculum;

- ensures a quick memorizing of terms and their definition, since the term to be found on the crossword the crossword should be laconic, clear, and precise;

- stimulates attention, memory, logical thinking and speech.

A student trying to compose a crossword reads the topic, compiles the contextual, comparative, summarizing, evaluating questions, looking for answers, finding and eventually understanding and learning the content. Therefore, in the international practice, crossword composing and solving is one of the most effective ways in the development of reading and comprehension skills of students. Crossword Rebus is an entertaining material for classroom learning that attracts students to make the lesson process more interesting, and provides assessment the knowledge both in group and individually. The Crossword Solution or Composition consists of the following steps:

- teaches to analyze the given question, choose the textbook for specific questions or puzzles; material is revised;

- teaches to interact within the group, develops independence and responsibility for the work; 
- develops creative thinking and skills of the trainee related to his/her spelling when composing a crossword independently, enhances the level of knowledge and vocabulary;

- ensures understanding of basic concepts and terms of the subject, spelling literacy, evaluating the level of knowledge acquisition, interdisciplinary and intradisciplinary integration;

- trains memory, and shapes sharp, flexible thinking and improved dictionary skills;

- increases the interest in studying the subject, theory and willingness to work with book.

Examining the student thoroughly, showing and explaining his/her weaknesses is vital to his/her future activity. There is no other way of revealing and eliminating these vulnerabilities in the "chain" of knowledge. Composing and solving crossword puzzle repeatedly by each student and on each or several topics helps to solve this problem. The students may enthusiastically compose crossword puzzles at classes and home.

The study on the English language as a second-language learning technology mainly focused on the use of crossword puzzles in expanding vocabulary [20]. It was concluded that the use of crossword puzzles in teaching English as a second language is an effective strategy for lexicon teaching. The study showed that the use of crosswords is of pedagogical significance, as they help pupils (students) expand their vocabulary and deepen their English lexicon skills.

Thus, the use of intellectual tests, crossword and other educational games in the classes provides favorable environment for students, and helps to study materials or foreign languages.

\section{Conclusion}

There is a need to expand the research to improve the quality of training of young people with the use of information technology. Regular use of educational games, interactive tests and crosswords, as well as holding periodic contests can effectively address the above-mentioned problems, making the learning process more 'colorful' and interesting, adopting new terms, and increasing motivation of students and their intelligence.

Some of the challenges facing the teaching of Informatics in Azerbaijan and the analysis of non-standard methods used in the educational systems of foreign countries necessitate the following tasks:

- classification of educational computer games;

- preparation of interactive tests, crossword puzzles and simple games for the periodical analysis and progress tracking of the intelligence of the pupils of elementary classes and V-XI grades on Informatics;

- preparation of teaching methods, algorithms using mentioned teaching tools taking into account the psychological and pedagogical aspects;

- Use of these tools by teachers and proposing methods to develop teaching skills;

- Preparation of different integrative tests and crossword puzzles for extracurricular activities;

- Preparation of a sample web site of certain destination, and uploading prepared samples and resources generated by teachers, pupils and students on the web site;

- Holding periodical game-competitions among schools and classes.

It should be noted that, based on current terminological dictionaries included in the National Terminology Information System web portal [21], various electronic terminological tests, crosswords, computer games can be prepared according to difficulty levels (all grades of education). The level of intelligence of individuals can be evaluated through these online terminological products and services. 


\section{References}

1. Badmaeva N. Ts., Motivational mechanisms of the development of general mental abilities. // Bulletin of the Buryat State University, Series "Psychology", 2005, pp. 126-131.

2. Nikitin P.V., Gorokhova R.I., Zaykov A.S. The use of computer games as a factor of improving the quality of teaching computer science // Educational Technologies and Society, Kazan National Research Technological University (Kazan), pp. 397-409.

3. Terminological tests, https://www.studopedia.su/14_134923_terminologicheskie-testi.html

4. Hotz R.L. When Gaming Is Good for You, The Wall Street Journal, 2012, https://www.wsj.com/articles/SB10001424052970203458604577263273943183932

5. Terminological test-simulator on History, http://www.xn--i1abbnckbmcl9fb.xn--p1ai/

6. http://www.institute-of-progressive-education-and-learning.org/elearning/elearningeducational-games

7. Heineman D.S..Thinking about Video Games: Interviews with the Experts, 2015, Indiana University Press, 268 p.

8. Mardanov M., Aghamaliyev R., Meherabov A., Gardashov T. Monitoring and Evaluation in Education System, Baku, Elm, 2010, 210 p.

9. The_Oregon_Trail. https://ru.wikipedia.org

10. https://www.amazon.com/LeapFrog-Leapster-Learning-Game-System/dp/B000BTNQUQ

11. Klopfer E. Augmented Learning: Research and Design of Mobile Educational Games [ebook]. MIT Press; 2008. Available from: eBook Collection, Ipswich, MA. Reprint edition 2011, 272 p.

12. De Gloria A., Bellotti F., Berta R., Lavagnino E. Serious Games for education and training University of Genoa // International Journal of Serious Games. Vol 1, No 1, 2014, https://www.researchgate.net/profile/Alessandro_De_Gloria2/publication/286244094_Serio us_Games_for_education_and_training/links/56af388708ae28588c62ecf9/Serious-Gamesfor-education-and-training.pdf

13. http://www.cmsw.mit.edu

14. https://www.nap.edu

15. https://www.brainpop.com

16. https://www.jr.brainpop.com/games

17. https://www.icivics.org

18. The River City Project. http://www.muve.gse.harvard.edu/rivercityproject/

19. http://www.eduneo.ru/uchebnyj-krossvord-kak-i-gde-sostavit

20. Njoroge M.C., Ndung'u R.W., Gathigia M.G. The Use of Crossword Puzzles as a Vocabulary Learning Strategy: A Case of English as Second Language in Kenyan Secondary Schools // International Journal of Current Research, Vol. 5, Issue, 02, February, 2013, pp. 313-321.

21. http://www.azterm.az 